Special issue of the 2nd International Conference on Computational and Experimental Science and Engineering (ICCESEN 2015)

\title{
Radiation Exposure of Medical Staff in Interventional Radiology
}

\author{
Ü. KARA ${ }^{a, *}$ AND I. AKKURT ${ }^{b}$ \\ ${ }^{a}$ Suleyman Demirel University, Vocational School of Healt Services, Isparta, Turkey \\ ${ }^{b}$ Suleyman Demirel University, Physics Department, Isparta, Turkey
}

\begin{abstract}
The aim of this study was to assess the radiation dose received by doctors, nurses, X-ray technician medical staff during cardiac catheterization in a representative sample of the staff in our angiography department. Radiation from X-ray machines can cause serious side effects. Radiation exposure of angiography staff (doctors, nurses, medical staff and X-ray technicians) has been recognized as a necessary hazard in angiography department. The purpose of our work is to determine angiography staff radiation doses during interventional radiology, to identify procedures associated with higher radiation doses, and to determine the effects of various parameters on staff doses. This study was performed at Suleyman Demirel University Medical Faculty Hospital. The procedure of study was performed in an interventional radiology department. We have recorded radiation doses data during all related imaging procedures performed as a part of department activity. The distances from the X-ray tube were $0 \mathrm{~cm}$ (doctor), $60 \mathrm{~cm}$ (nurse), $120 \mathrm{~cm}$ (medical staff) and $180 \mathrm{~cm}$ (X-ray technician). It is important to understand the radiation effects on medical staff in interventional radiology procedures. Determinants of radiation risk include not only radiation dose levels but also medical staff number, ages, gender and their position. These factors can increase or decrease the risk of exposure.
\end{abstract}

DOI: 10.12693/APhysPolA.130.404

PACS/topics: 87.50.yk, 87.57.uk

\section{Introduction}

Radiation is widely used in a variety of fields, especially in medical science. Radiology, nuclear medicine, radiation oncology clinics use radiation for diagnosis and treatment. Radiology clinics often use radiation for diagnosis. However the interventional radiology is a diagnostic and treatment method for performing image-guided procedures. The concept of interventional radiology is to diagnose and treat patients using the least invasive techniques currently available, in order to minimize risk of harming the patient and to improve health outcomes. These procedures have minimum risk, minimum pain and fast recovery time compared to open surgery procedures. Interventional radiology procedures are either diagnostic or therapeutic. Interventional radiology may also be classified according to anatomical region and may be further subdivided into vascular and non-vascular procedures [1].

A number of cases of deterministic effects arising from interventional radiology have been reported $[2,3]$. At the 1995 meeting of the Radiological Society of North America, a review of radiation induced skin injuries from fluoroscopy by the US Food and Drug Administration (FDA), was presented [4]. Recently Vañó et al. have reported a series of patients in whom deterministic skin injuries had been observed, following radiofrequency ablation cardiac interventional procedures [5].

These work is intended as a guide to the lowest practically achievable dose for staff of the Suleyman Demirel University Medical Faculty Hospital, interventional radiology department.

\footnotetext{
*corresponding author; e-mail: umitkara@sdu.edu.tr
}

\section{Materials and methods}

In this study, we have worked at Interventional Radiology Department in Suleyman Demirel Research Hospital which uses fluoroscopy medical imaging unit (Shimadzu/Bransist Safire VC17). We have measured radiation doses received by medical staff and doctors during interventional radiology. We have repeated the measurements for one month using Polimaster PM-1621 X-ray and gamma-ray radiation personal dosimeter in interventional radiology (Table I).

TABLE I

Features of personal dosimeter PM-1621.

\begin{tabular}{|c|c|}
\hline Detector & GM tube \\
\hline DER measurement range & $0.1 \mu \mathrm{Sv} / \mathrm{h}-100 \mathrm{mSv} / \mathrm{h}$ \\
\hline Dose rate accuracy & $\begin{array}{c} \pm(15+0.0015 / H+0.01 H) \% \\
(\text { in range } 0.1 \mu \mathrm{Sv} / \mathrm{h}-0.1 \mathrm{~Sv} / \mathrm{h}, \\
\text { where } H \text { is the dose rate } \\
\text { in } \mathrm{mSv} / \mathrm{h})\end{array}$ \\
\hline DE measurement range & $\begin{array}{c}0.01 \mu \mathrm{Sv}-9.99 \mathrm{~Sv} \\
(1 \mu \mathrm{R}-999 \mathrm{R})\end{array}$ \\
\hline Dose accuracy & $\begin{array}{c} \pm 15 \% \text { (in range } 1 \mu \mathrm{Sv}-9.99 \mathrm{~Sv} \\
(100 \mu \mathrm{R}-999 \mathrm{R}))\end{array}$ \\
\hline Energy range & $10.0 \mathrm{KeV}-20.0 \mathrm{MeV}$ \\
\hline $\begin{array}{c}\text { Energy response relative } \\
\text { to } 0.662 \mathrm{MeV}\left({ }^{137} \mathrm{Cs}\right) \\
\end{array}$ & $\pm 30 \%$ \\
\hline $\begin{array}{c}\text { Survive after momentary } \\
\text { influence of maximum } \\
\text { permissible gamma } \\
\text { radiation within } 5 \text { min. }\end{array}$ & $1 \mathrm{~Sv} / \mathrm{h}(100 \mathrm{R} / \mathrm{h})$ \\
\hline
\end{tabular}


When we have measured the radiation doses, doctors and medical staff were in their routine locations. The distances from these locations to the X-ray tube were found to be $0 \mathrm{~cm}$ for doctor, $60 \mathrm{~cm}$ for nurse, $120 \mathrm{~cm}$ for medical staff and $180 \mathrm{~cm}$ for the X-ray technician. Three positions of the X-ray tube were considered: position number 1, X-ray tube is located beside the staff, position number 2, X-ray tube is located under the patient, number 3, X-ray tube is located opposite the staff (Fig. 1).

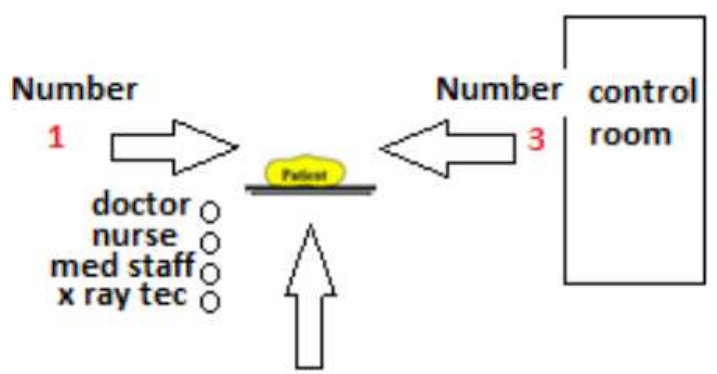

Number 2

Fig. 1. Considered X-ray tube positions.

The mean dose values in units of $\mu \mathrm{Sv} / \mathrm{h}$ are summarized in the Tables II and III.

TABLE II

Interventional radiology radiation doses.

\begin{tabular}{|c|c|c|c|c|c|}
\hline X-ray tube position & \multicolumn{5}{|c|}{ Radiation doses } \\
\hline Number 1 & \multicolumn{2}{|c|}{ Fluoroscopy time } & \multicolumn{2}{|c|}{ Radiation exposure } & \\
\hline $\begin{array}{l}\text { Distance from } \\
\text { X-ray tube }[\mathrm{cm}]\end{array}$ & $\mid \mu \mathrm{Sv} / \mathrm{h}]$ & {$[\mathrm{mR} / \mathrm{h}]$} & $\mid \mu \mathrm{Sv} / \mathrm{h}]$ & {$[\mathrm{mR} / \mathrm{h}]$} & $\begin{array}{c}\text { Radiation } \\
\text { workers }\end{array}$ \\
\hline Origin & 0.04 & 15 & 0.02 & 15 & Doctor \\
\hline 60 & 0.04 & 7 & 0.01 & 10 & Nurse \\
\hline 120 & 0.01 & 5 & 0.01 & 5 & Med. staff \\
\hline 180 & 0.01 & 2 & 0.005 & 3 & X-ray techn. \\
\hline Number 2 & \multicolumn{2}{|c|}{ Fluoroscopy time } & \multicolumn{2}{|c|}{ Radiation exposure } & \\
\hline $\begin{array}{c}\text { Distance from } \\
\text { X-ray tube }[\mathrm{cm}]\end{array}$ & {$[\mu \mathrm{Sv} / \mathrm{h}]$} & {$[\mathrm{mR} / \mathrm{h}]$} & {$[\mu \mathrm{Sv} / \mathrm{h}]$} & {$[\mathrm{mR} / \mathrm{h}]$} & $\begin{array}{l}\text { Radiation } \\
\text { workers }\end{array}$ \\
\hline Orgin & 0.06 & 16 & 0.03 & 17 & Doctor \\
\hline 60 & 0.04 & 13 & 0.02 & 15 & Nurse \\
\hline 120 & 0.03 & 7 & 0.01 & 8 & Med. staff \\
\hline 180 & 0.02 & 2 & 0.005 & 4 & X-ray techn. \\
\hline Number 3 & \multicolumn{4}{|c|}{ Fluoroscopy time Radiation exposure } & \\
\hline $\begin{array}{c}\text { Distance from } \\
\text { X-ray tube }[\mathrm{cm}]\end{array}$ & $|[\mu \mathrm{Sv} / \mathrm{h}]|$ & {$[\mathrm{mR} / \mathrm{h}]$} & {$[\mu \mathrm{Sv} / \mathrm{h}]$} & {$[\mathrm{mR} / \mathrm{h}]$} & $\begin{array}{l}\text { Radiation } \\
\text { workers }\end{array}$ \\
\hline Orgin & 0.03 & 6 & 0.02 & 8 & Doctor \\
\hline 60 & 0.04 & 10 & 0.05 & 12 & Nurse \\
\hline 120 & 0.02 & 6 & 0.01 & 6 & Med. staff \\
\hline 180 & 0.01 & 2 & 0.01 & 3 & X-ray techn. \\
\hline
\end{tabular}

\section{Results}

The dosimetric data for three different locations, as a function of distance from the X-ray tube, are shown in Figs. 2-4. The maximum dose is found at origin and at $60 \mathrm{~cm}$. Radiation doses decreased with the increasing distance from the beam central axis, for a given location of X-ray tube. Figure 5 shows that doctor and nurse have taken a high radiation doses and the other staff have taken smaller radiation doses.
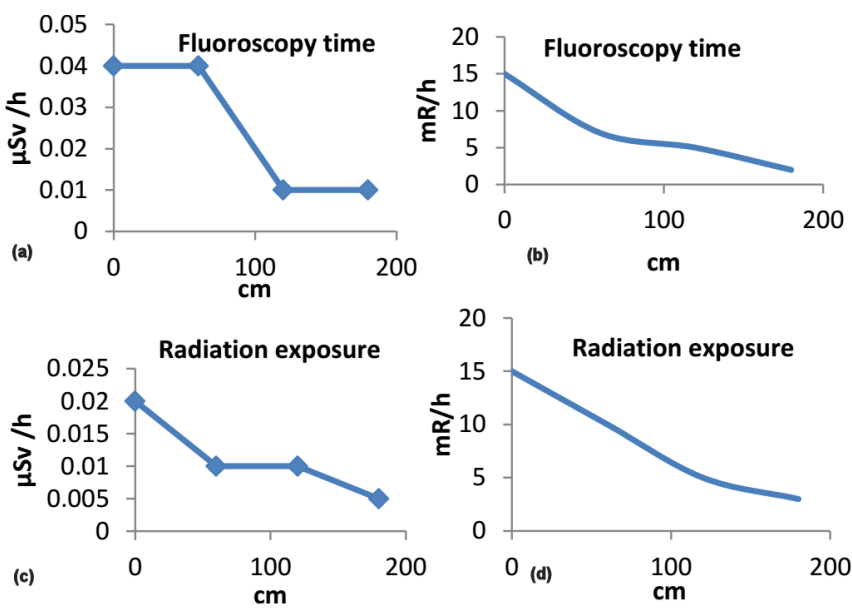

Fig. 2. Measured radiation dose as function of distance at X-ray position number 1.
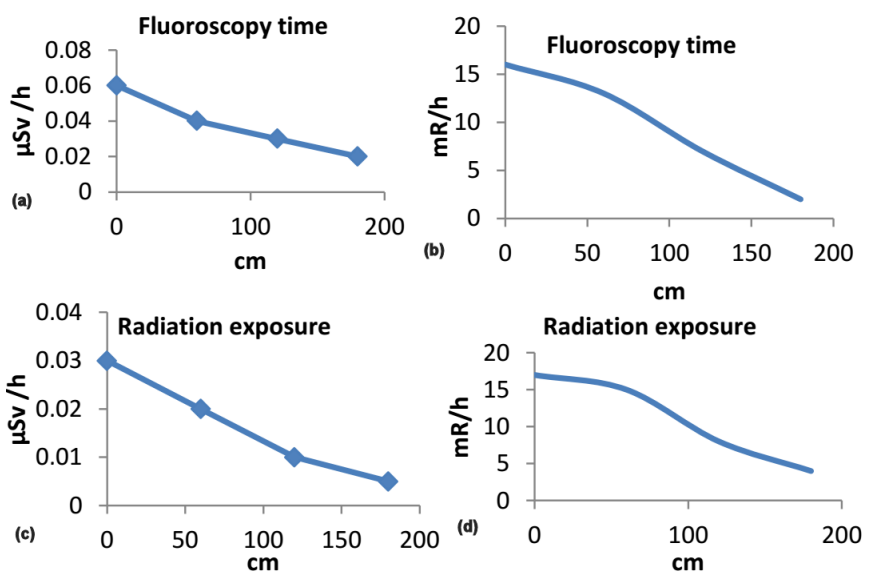

Fig. 3. Measured radiation dose as function of distance at X-ray position number 2 .
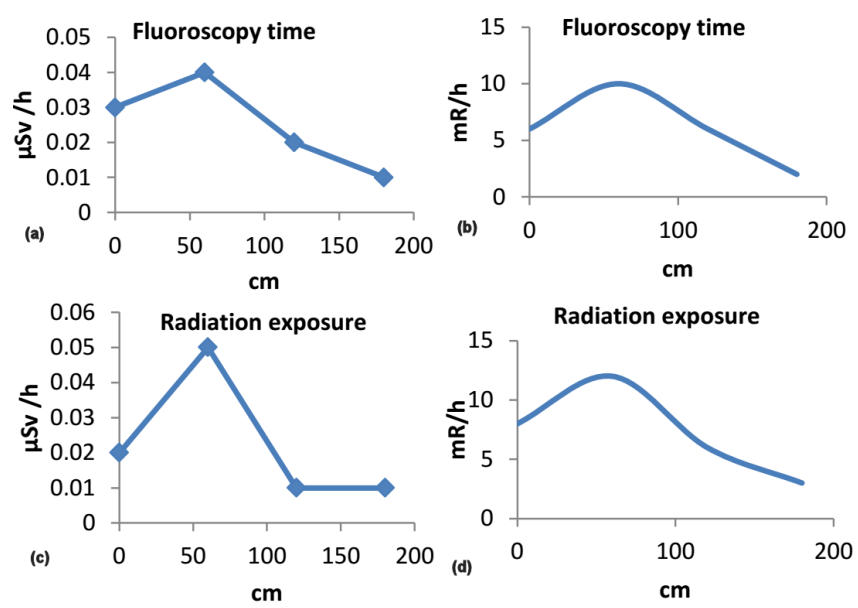

Fig. 4. Measured radiation dose as function of distance at X-ray position number 3 . 
TABLE III

Interventional radiology daily and month radiation doses.

\begin{tabular}{c|c|c|c}
\hline \hline \multicolumn{2}{c|}{ Daily average doses } \\
$\begin{array}{c}\text { Fluoroscopy } \\
\text { time }\end{array}$ & $\begin{array}{c}\text { Radiation } \\
\text { exposure }\end{array}$ & $\begin{array}{c}\text { Total monthly } \\
\text { doses }\end{array}$ & $\begin{array}{c}\text { Radiation } \\
\text { workers }\end{array}$ \\
\hline$[\mu \mathrm{Sv} / \mathrm{h}]$ & {$[\mu \mathrm{Sv} / \mathrm{h}]$} & {$[\mu \mathrm{Sv} / \mathrm{h}]$} & \\
\hline 4 & 2 & 4 & Doctor \\
4 & 1 & 4 & Nurse \\
1 & 1 & 1.8 & Med. staff \\
1 & 0.5 & 2.1 & X-ray techn.
\end{tabular}
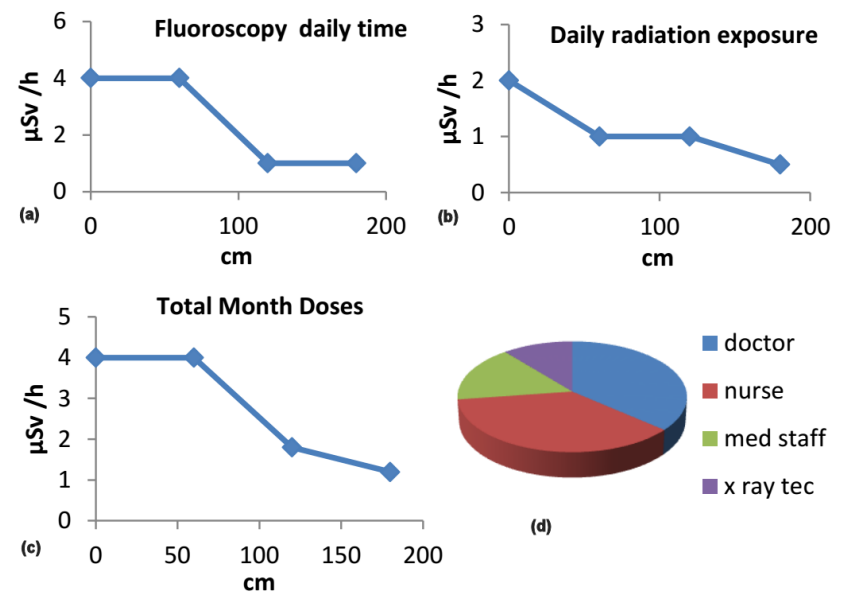

Fig. 5. Measured daily and monthly doses of radiation workers.

\section{Discussion}

Interventional radiology using X-rays, such as fluoroscopy, is the method that provides real-time X-ray imaging that is especially useful for guiding a variety of interventional procedures. Some fluoroscopical procedures are associated with a risk of radiation injury to the skin. The majority of instances reported in the literature or to the United States Food and Drug Administration (FDA) result from cardiac radiofrequency ablation or coronary angioplasty $[3,6]$. Some reported skin injuries were associated with transjugular intrahepatic portosystemic shunt (TIPS) creation, renal angioplasty, multiple hepatic/biliary procedures, or embolization [1, 3, 6-9]. In all patients the risk of a cancer from the exposure is not a major concern when compared to the benefits of the procedure. But the medical staff must be careful because of the cancer risk related to radiation exposure. Doses are likely to be higher when these procedures are performed with fluoroscopic equipment that lacks state-of-the-art dose-reduction features or by operators who lack adequate training in radiation protection.

\section{Conclusions}

Nearly all hospitals use ionizing radiation for diagnosis. Each hospital should have a radiation protection and safety council, and all departments that use radiation should have local rules. In our hospital there is a radiation protection committee but sometimes it is not enough. All medical staff should be taught "what is radiation and what is radiation safety and protection" in interventional radiology. Medical staff should receive radiation protection education in interventional radiology. If medical staff (doctors, nurses, etc.) learn radiation protection safety, they can protect themselves.

\section{References}

[1] International Commission on Radiological Protection, Protection of the patient in diagnostic radiology, ICRP Publication 34, Vol. 9, Pergamon Press, 1982.

[2] C.L. Lashbaugh, K.F. Hubner, S.A. Fry, in: Proc. NCRP symp., National Council on Radiation Protection, 1982, p. 46.

[3] W. Huda, K.R. Peters, Radiology 193, 642 (1994).

[4] T. Shope, Food and Drug Administration, USA, Internet Site.

[5] T.B. Shope, Radiology 197, 449 (1995).

[6] T.R. Koenig, F.A. Mettler, L.K. Wagner, AJR Am. J. Roentgenol. 177, 13 (2001).

[7] D.A. Lichtenstein, L. Klapholz, D.A. Vardy, I. Leichteret, M. Mosseri, S.N. Klaus, L.T. Gilead, Arch. Dermatol. 132, 663 (1996).

[8] R.W. Gunther, D. Vorwerk, C. Pfannenstiel, in: Forschung mit Rontgenstrahlen, Eds. F.H.W. Henck, E. Macheranch, Springer, Berlin 1995, p. 237.

[9] E. Vañó, L. Arranz, J.M. Sastre, C. Moro, A. Ledo, M.T. Gárate, I. Minguez, Int. J. Radiol. Radiat. Oncol. Sci. 71, 510 (1998). 